\title{
STUDI PERENCANAAN INSTALASI PENGOLAHAN LIMBAH LINDI SEBAGAI KONTROL PEMENUHAN BAKU MUTU SESUAI KEPMEN 03/91 (STUDI KASUS PADA TPA SUPIT URANG MALANG)
}

\author{
Chairil Saleh \\ Fakultas Teknik Jurusan Teknik Sipil Universitas Muhammadiyah Malang \\ Alamat Korespondensi : Jl. Raya Tlogomas, No.246 Malang \\ Email: chairil@umm.ac.id
}

\begin{abstract}
The processing of lye waste instalation is a processing lye waste leachate discharged into water bodies do not pollute the environment.Harm caused leachatecan kill the organisms - organisms if the leachate is discharged directly into water bodies without prior treatment.

Need for storage pondsfor leachate treatment plant, and therefore the capacity to design ponds need to know how the leachate discharges.Required to discharge leachate storage ponds designed to meet the volume of pond water leachate.From the analysis of the leachate discharge obtained by $9.43 \mathrm{~m}^{3} /$ day. And the production of leachate was $0.8 \mathrm{~m}^{3} /$ day. Levels of waste treatment unit COD $=8960 \mathrm{mg} / 1$ and $\mathrm{BOD}_{5}=3968.293 \mathrm{mg} / 1$, after going through the waste treatment plant to be COD $=298.67 \mathrm{mg} / 1$ and $\mathrm{BOD}_{5}=88.18 \mathrm{mg} / 1$. From the processing of these three levels in an already meets the standard group III cross section pond 03/91.
\end{abstract}

Keywords : Water leachate, storage ponds, $\mathrm{COD}$ and $\mathrm{BOD}_{5}$.

\section{PENDAHULUAN}

Masalah pembuangan sampah merupakan salah satu isu utama bagi setiap kota di indonesia. Pertumbuhan penduduk dan kemajuan tingkat perekonomian di suatu kota secara langsung mempengaruhi peningkatan jumlah sampah. Sebagai contoh kota seperti malang setiap harinya memproduksi sampah sampai 400 ton sampah. Sampah tersebut jika tidak dikelola dengan baik maka akan mempengaruhi tigkat kebersihan dan mencemari lingkungan kota, yang pada akhirnya menurunkan tingkat kesehatan masyarakat.

Air lindi dapat merembes melalui tanah dan dimungkinkan pula akan mencemari air tanah yang ada di lokasi Tempat Pembuangan Akhir. Perembesan ini sangat tergantung dari sifat fisik tanah dasar TPA seperti porositas, permeabilitas dan tekanan piezometrik. Air lindi akan merembes melalui tanah secara perlahan, jika terdapat aliran air tanah di bawah lokasi TPA, maka air lindi akan mencemari aliran tersebut dengan kandungan zat yang cukup berbahaya bagi lingkungan. (Alfiandy, 2003).

\section{Permasalahan}

Meningkatnya jumlah penduduk Kota Malang mengakibatkan peningkatan volume sampah yang berdampak pada kapasitas tampung dan masa pakai TPA Supit Urang. Belum adanya pengolahan air limbah lindi pada TPA Supit Urang.

\section{Tujuan}

Tujuan dari penelitian ini adalah Mengetahui berapakah debit air lindi pada TPA Supit Urang, Mengetahui berapakah kapasitas kolam penampung air lindi pada TPA Supit Urang dan Mengetahui instalasi pengolahan air limbah lindipada TPA Supit Urang.

\section{Manfaat}

Penelitian yang dilakukan nantinya diharapkan dapat bermanfaat bagi masyarakat, pemerintah daerah maupun terhadap perkembangan ilmu pengetahuan dan teknologi. 


\section{Definisi Sampah}

Menurut Pichtel, J. (2005), sampah merupakan material sisa yang tidak diinginkan setelah berakhirnya suatu proses.

\section{Analisa Timbulan Sampah}

Menurut Smith, dkk (2001), perkiraan jumlah penduduk ini dapat dilakukan dengan menghitung rasio laju pertumbuhan penduduk beberapa tahun pada tahun-tahun sebelumnya.

\section{Lapisan Pendukung.}

Lapisan pendukung ini merupakan lapisan pada dasar landfill yang dapat membantu dalam kontrol terhadap lindi dan perlindungan terhadap sistem penyalur dan pengumpul lindi (Tchobanoglous, Theisen, dan Vigil, 1993).

\section{Kolam Pengolahan}

Kolam stabilisasi atau kolam oksidasi merupakan suatu kolam yang terdiri atas tanggul dengan aliran air buangan (influen) yang laminer sehingga menyebabkan terjadinya aktivitas mikroorganisme.

Kolam stabilisasi ini selain dapat menurunkan kadar BOD dan COD juga dapat menurunkan jumlah fecal coli yang ada dalam leachate. Namun untuk pengolahan lindi sebaiknya menggunakan kolam anaerobik/fakultatif karena sangat tingginya kadar BOD (Alfiandy, 2003).

\section{Kolam Aerasi}

Kolam aerasi merupakan kolam yang berfungsi mengoksidasi air buangan yang mana kebutuhan oksigennya dipenuhi dengan proses aerasi. Pada prinsipnya, fungsi pengolahan ini adalah mengkonvensi air buangan menjadi komponen-komponen yang lebih sederhana dengan cara oksidasi (Alfiandy, 2003).

\section{Land Treatment (Rapid-Infiltrated Plant)}

Matoda Rapid Infiltrated Plant adalah metoda pengolahan lindi dengan cara meresapkan cairan lindi pada suatu lahan yang ditanami tumbuhan tertentu (Alfiandy, 2003).

\section{METODE PENELITIAN}

Kondisi Umum Wilayah Studi

Area luas lahan TPA yaitu 13,2 Ha, dan luas kantor dan taman $2 \mathrm{Ha}$. Dan adanya penambahan area 10 Ha untuk rehabilitasi TPA Supit Urang yang dilakukan oleh Pemkot Malang. Sehingga Total Area keseluruhan pengembangan area TPA menjadi 25,2 Ha. TPA Supit Urang terletak di Kelurahan Mulyorejo Kecamatan Sukun yang batas-batas sebagai berikut

- Sebelah utara : berbatasan dengan sungai Sumber Songo dengan jarak $\pm 300 \mathrm{~m}$

- Sebelah timur : tempat permukiman penduduk dengan jarak $\pm 700 \mathrm{~m}$

- Sebelah selatan : berbatasan dengan sungai Gandulan dengan jarak $\pm 200 \mathrm{~m}$

- Sebelahbarat :merupakan perbukitan dan lembah

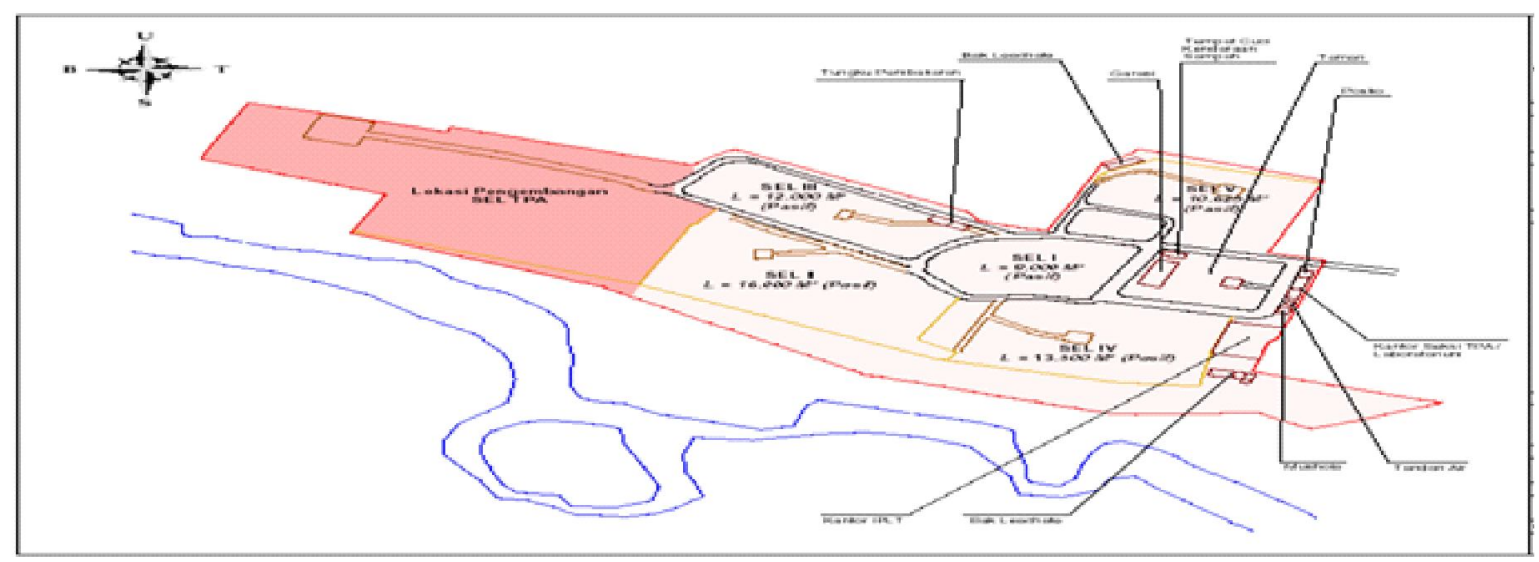

Sumber: Badan Perencana Pembangunan Kota (BAPPEKO) Malang (2007)

Gambar 1. Layout TPA Supit Urang 


\section{Tahapan Studi Perencanaan.}

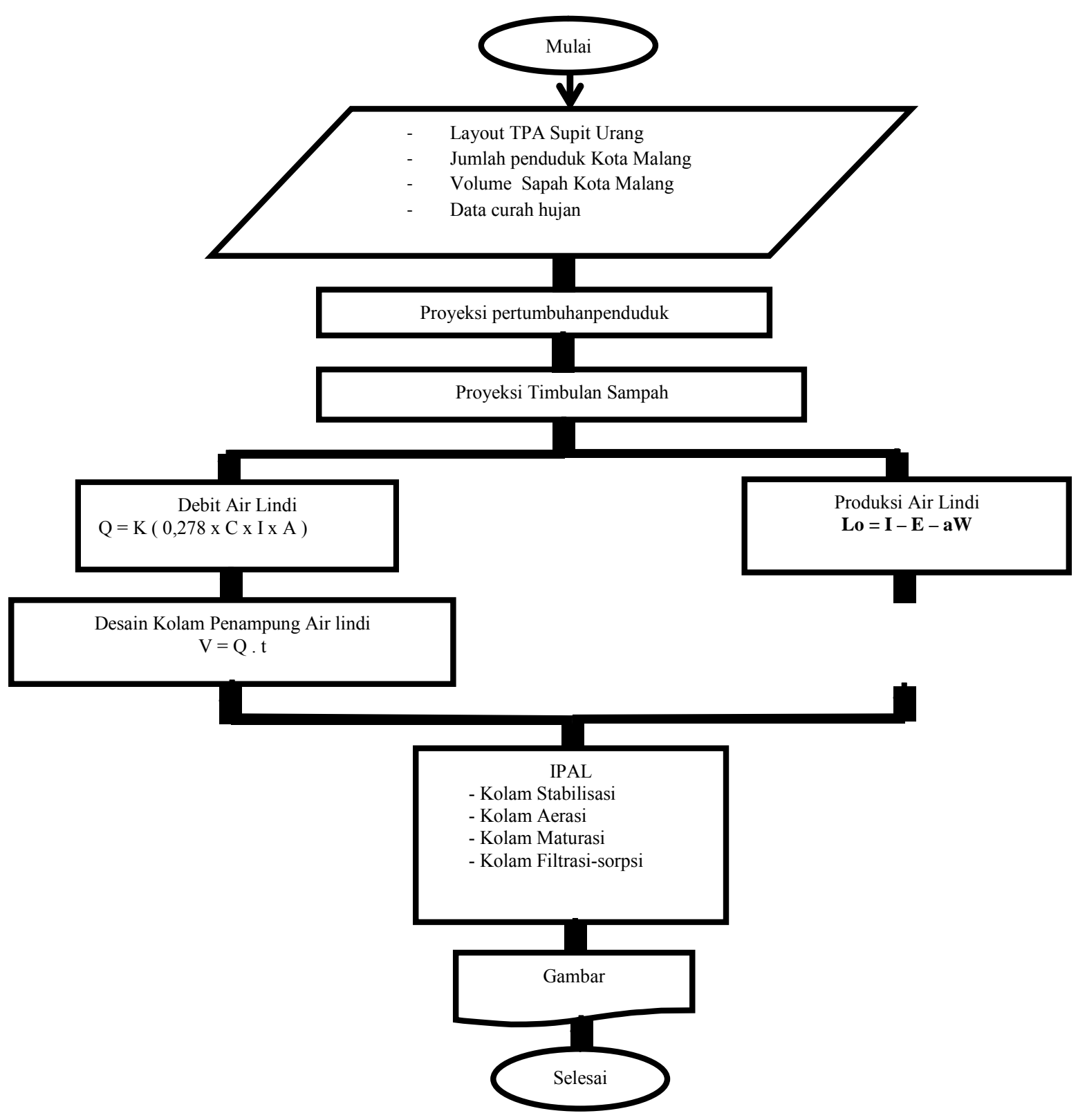

\section{Gambar 2. Diagram Alir Penelitian}

\section{HASIL DAN PEMBAHASAN}

\section{Proyeksi Jumlah Penduduk}

MenurutKlosterman, 1990 untuk proyeksi jumlah penduduk ada tiga metode yang sering digunakan yaitu :Metode Aritmatik, Metode Geometrik, dan Metode Least Square. Sebelum penentuan terhadap metode mana yang akan digunakan, dilakukan perhitungan nilai korelasi menggunakan ketiga metode yang telah disebutkan di atas. Metode yang menghasilkan nilai koefisien koreasi mendekati 1 adalah yang akan dipilih untuk menghitung proyeksi penduduk. Menurut Smith, Tayman dan Swanson (2001), Perhitungan nilai koefisien korelasi untuk masing-masing metode dimana digunakan Persamaan :

$$
r=\frac{\mathrm{n}\left(\sum \mathrm{xy}\right)-\left(\sum x\right)\left(\sum \mathrm{y}\right)}{\sqrt{\left.\left\{\mathrm{n}\left(\sum \mathrm{y}^{2}\right)-\left(\sum \mathrm{y}\right)^{2}\right)\right\}\left\{\mathrm{n}\left(\sum \mathrm{x}^{2}\right)-\left(\sum_{\mathrm{x}}\right) 2\right\}}}
$$

Dari ketiga perhitungan di atas diketahui bahwa Metode Geometri memiliki nilai koefisien yang paling mendekati satu, sehingga metode ini yang akan digunakan untuk memproyeksi jumlah penduduk. Dari 
jumlah hasil proyeksi penduduk Kota Malang diperolehjumlah penduduk di tahun 2031 yaitu 961.599 jiwa.

\section{Tabel 1. Prediksi Volume dan jumlah Sampah Kota Malang Per orang per Hari}

\begin{tabular}{llcrcc}
\hline No & Kecamatan & $\begin{array}{c}\text { Jumlah } \\
\text { Penduduk } \\
\text { Tahun } \\
2010\end{array}$ & $\begin{array}{c}\text { Volume } \\
\text { Sampah }\end{array}$ & $\begin{array}{c}\text { Volume } \\
\text { Sampah }\end{array}$ & $\begin{array}{c}\text { Jumlah } \\
\text { Sampah }\end{array}$ \\
& & $\mathrm{m}^{3} /$ Hari & $\mathrm{m}^{3} / \mathrm{org} / \mathrm{hr}$ & $\mathrm{kg} / \mathrm{org} / \mathrm{hari}$ \\
\hline 1 & Klojen & 105901 & 257 & 0.002427 & 0.8493782 \\
2 & Blimbing & 172333 & 275 & 0.001596 & 0.5585117 \\
& Kedung & & & & \\
3 & Kandang & 174477 & 222 & 0.001272 & 0.4453309 \\
4 & Sukun & 181513 & 181 & 0.000997 & 0.3490108 \\
5 & Lowokwaru & 186013 & 180 & 0.000968 & 0.338686 \\
\hline \multicolumn{7}{c}{ Rata - rata } & & $\mathbf{0 . 0 0 1 4 5 2}$ & $\mathbf{0 . 5 0 8 1 8 4}$ \\
\hline
\end{tabular}

Sumber : Hasil Analisis Data

Dari hasil tabel 1 maka di ketahui volume sampah harinya adalah $1191 \mathrm{~m}^{3} /$ hari dan setelah terkompaksi menjadi $643.14 \mathrm{~m}^{3} /$ hari.maka di peroleh jumlah volume sampah per tahunya adalah $\mathbf{8 . 6 0 8 . 1 8 3} \mathrm{m}^{3} /$ hari, dan setelah terkompaksi $\mathbf{4 . 6 4 8 . 4 1 9} \mathrm{m}^{3} /$ hari.

\section{Desain area penimbunan}

Lahan efektif landfill TPA Supit Urang direncanakan terdiri atas 3 (tiga) Zona dengan luas keseluruhan seluas $\pm 19,044236$ ha (termasuk jalan operasi bagian dalam). Area landfill sampah kota dibagi menjadi 3 (tiga) Zona, dengan luas masingmasing pada gambar 3 sebagai berikut:

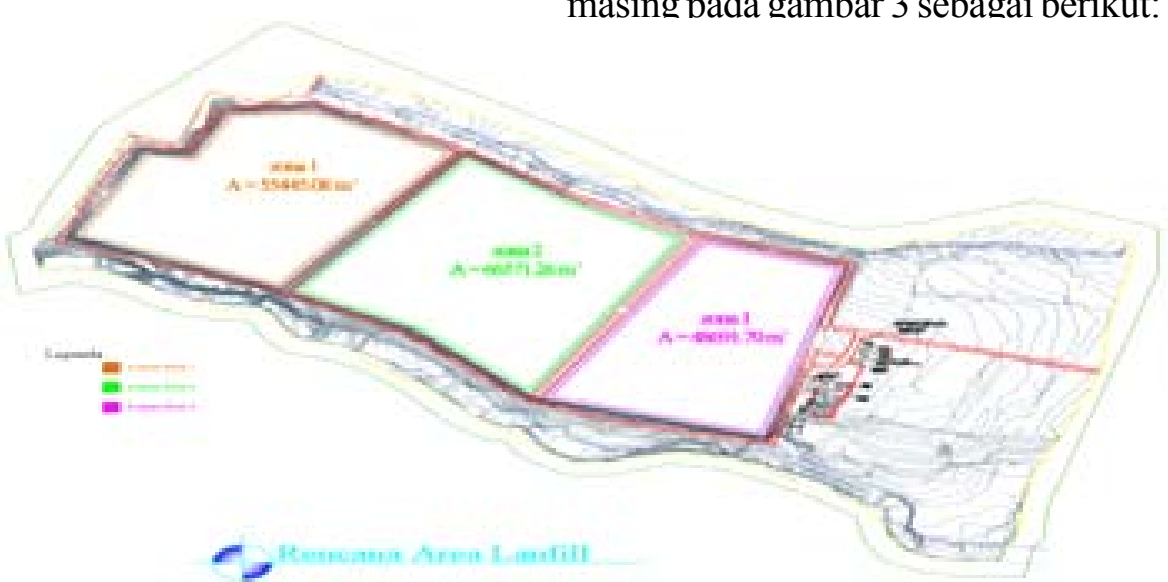

Gambar 3. Rencana Area Lanfill

-Zona $1: 55445,08 \mathrm{~m}^{2}$

-Zona 2 : 66571,26 $\mathrm{m}^{2}$

Perhitungan kapasitas Tempat Pembuangan Akhir Sampah Supit Urang ini dapat menampung sampah sekitar $\mathbf{5 . 4 8 7 . 8 9 6 . 0 8} \mathrm{m}^{3}$ sampah kota atau diperkirakan dapat melayani regional Kota Malang sampai dengan jangka waktu \pm 20 tahun.

\section{Timbulan Lindi (leachate)}

Sehingga dengan mengetahui data curah hujan selama 10 tahun, maka akan dapat diperkirakan debit atau jumlah air lindi yang timbul. Perkiraan debit air 
lindi diperoleh luasan galian tempat timbulan sampah dikalikan dengan intensitas hujan dikalikan koefisien pengaliran dikalikan dengan tetapan 0,278 dan dikalikan lagi dengan factor pendekatan. (Direktorat PLP, 1999).

$$
Q=K \times(0,278 \times C \times I \times A)
$$

Dimana :

$$
\begin{aligned}
& \mathrm{Q}=\text { debit rencana leachate } \mathrm{m}^{3} / \text { hari } \\
& \mathrm{K}=\text { faktor pendekatan }(0,60-0,70) \\
& \mathrm{C}=\text { koefisien pengaliran }(0,3-0,4) \\
& \mathrm{I}=\text { intensitas hujan }(\mathrm{mm} / \mathrm{hari}) \\
& \mathrm{A}=\text { luas galian tempat timbulan sampah }
\end{aligned}
$$

Dari hasil perhitungan debit air lindi maka di ketahui debit air hujan pada TPA Supit Urang adalah $9.43 \mathrm{~m}^{3} /$ hari.

\section{Produksi Air Lindi}

Menurut Martono Djoko Heru, 1996 perkiraan produksi air lindi dapat dihitung melalui metoda keseimbangan air. Produksi air lindi dapat diperkirakan dengan persamaan keseimbangan air seperti berikut :

$$
\mathbf{L o}=\mathbf{I}-\mathbf{E}-\mathbf{a W}
$$

Dimana :

$$
\begin{aligned}
& \mathrm{Lo}=\text { Produksi air lindi }\left(\mathrm{m}^{3} / \text { tahun }\right) \\
& \mathrm{I}=\text { Total masukan air }\left(\mathrm{m}^{3} / \text { tahun }\right) \\
& \mathrm{a}=\text { Kemampuan sampah menyerap air }\left(\mathrm{m}^{3} /\right. \\
& \text { ton sampah) } \\
& \mathrm{W}=\text { Berat sampah yang ditimbun (ton/tahun) }
\end{aligned}
$$

Dan produksi air lindai pada TPA Supit Urang Malang adalah $0,8 \mathrm{~m}^{3} /$ hari.

\section{Desain Kolam Penampung}

Kolam penampung adalah kolam yang hanya menampung air lindi dari setiap sell. pada perencanaan untuk TPA Supit Urang direncanakan dua kolam penampung yang masing-masing memiliki waktu detensi sekitar satu minggu. Dengan demikian dapat didesain dimensi kolam untuk penampung air lindi adalah sebagai berikut : a) Untuk kolam penampung pertama dengan debit timbulan lindi $\mathrm{Q}=19,56 \mathrm{~m}^{3} /$ hari, dengan waktu detensi 7 hari maka volume kolam $\mathrm{V}=160 \mathrm{~m}^{3}$. Jika kedalaman kolam 2,5 meter maka luas kolam total $\mathrm{A}=64 \mathrm{~m}^{2}$, dan dimensi kolam dengan panjang $8 \mathrm{~m}$, lebar $8 \mathrm{~m}$.

b) Untuk kolam penampung kedua dengan debit timbulan lindi $\mathrm{Q}=19,56 \mathrm{~m}^{3} /$ hari, dengan waktu

\begin{tabular}{|c|c|c|c|c|c|}
\hline $\begin{array}{c}\text { Bak } \\
\text { Pengolahan }\end{array}$ & $\begin{array}{c}\mathrm{t} \\
\text { (hari) }\end{array}$ & $\begin{array}{c}\text { Q } \\
\text { (m3/hari) }\end{array}$ & $\begin{array}{c}\text { Volume } \\
\text { (m3) }\end{array}$ & $\begin{array}{l}\mathrm{H} \\
\text { (m) }\end{array}$ & $\begin{array}{c}\mathrm{Px} \mathrm{L} \\
(\mathrm{m} \mathrm{x} \\
\mathrm{m})\end{array}$ \\
\hline $\begin{array}{l}\text { Kolam } \\
\text { Stabilisasi }\end{array}$ & 20 & 0,8 & 10 & 2 & $2 \times 4$ \\
\hline
\end{tabular}
detensi 7 hari maka volume kolam $\mathrm{V}=160 \mathrm{~m}^{3}$. Jika kedalaman kolam 2,5 meter maka luas kolam total $\mathrm{A}=64 \mathrm{~m}^{2}$, dan dimensi kolam dengan panjang $8 \mathrm{~m}$, lebar $8 \mathrm{~m}$. Jadi untuk kolam kedua ini di fungsikan apabila seketika kolam tampungan pertama melimpah.

\section{Desain Kolam Stabilisasi}

Kolam stabilisasi atau kolam oksidasi merupakan suatu kolam yang terdiri atas tanggul dengan aliran air buangan (influen) yang laminer sehingga menyebabkan terjadinya aktivitas mikroorganisme.

\section{Desain Kolam Aerasi Secara Mekanis}

Kolam aerasi merupakan kolam yang berfungsi mengoksidasi air buangan yang mana kebutuhan oksigennya dipenuhi dengan proses aerasi. Pada prinsipnya, fungsi pengolahan ini adalah mengkonvensi air buangan menjadi komponen-komponen yang lebih sederhana dengan cara oksidasi.

\section{Tabel 3. Rencana kolam Aerasi}

\begin{tabular}{cccccc}
\hline $\begin{array}{c}\text { Bak } \\
\text { Pengolahan }\end{array}$ & $\mathrm{t}$ & $\mathrm{Q}$ & Volume & $\mathrm{H}$ & $\begin{array}{c}\mathrm{P} \times \mathrm{L} \\
(\mathrm{mx}\end{array}$ \\
& (hari) & $(\mathrm{m} 3 /$ hari $)$ & $(\mathrm{m} 3)$ & $(\mathrm{m})$ & $\mathrm{m})$ \\
\hline $\begin{array}{l}\text { Kolam } \\
\text { Aerasi }\end{array}$ & 10 & 0,8 & 8 & 2 & $2 \times 2$ \\
\hline
\end{tabular}

\section{Desain Kolam Maturasi}

Kolam maturasi adalah pematangan. Sesuai dengan namanya, di kolam ini terjadi proses 
pematangan atau pembersihan terakhir air limbah dari pencemar berupa padatan tersuspensi, zat organik terlarut dan yang utama adalah reduksi bakteri.

\section{Tabel 4. Rencana kolam Maturasi}

\begin{tabular}{|c|c|c|c|c|c|}
\hline $\begin{array}{c}\text { Bak } \\
\text { Pengolahan }\end{array}$ & $\begin{array}{c}\mathrm{t} \\
\text { (hari) }\end{array}$ & $\begin{array}{c}\mathrm{Q} \\
\text { (m3/hari) }\end{array}$ & $\begin{array}{l}\text { Volume } \\
\text { (m3) }\end{array}$ & $\begin{array}{l}\mathrm{H} \\
(\mathrm{m})\end{array}$ & $\begin{array}{c}\mathrm{P} \times \mathrm{L} \\
(\mathrm{m} \mathrm{x} \\
\mathrm{m})\end{array}$ \\
\hline $\begin{array}{l}\text { Kolam } \\
\text { Maturasi }\end{array}$ & 15 & 0,8 & 16 & 2 & $2 \times 4$ \\
\hline
\end{tabular}

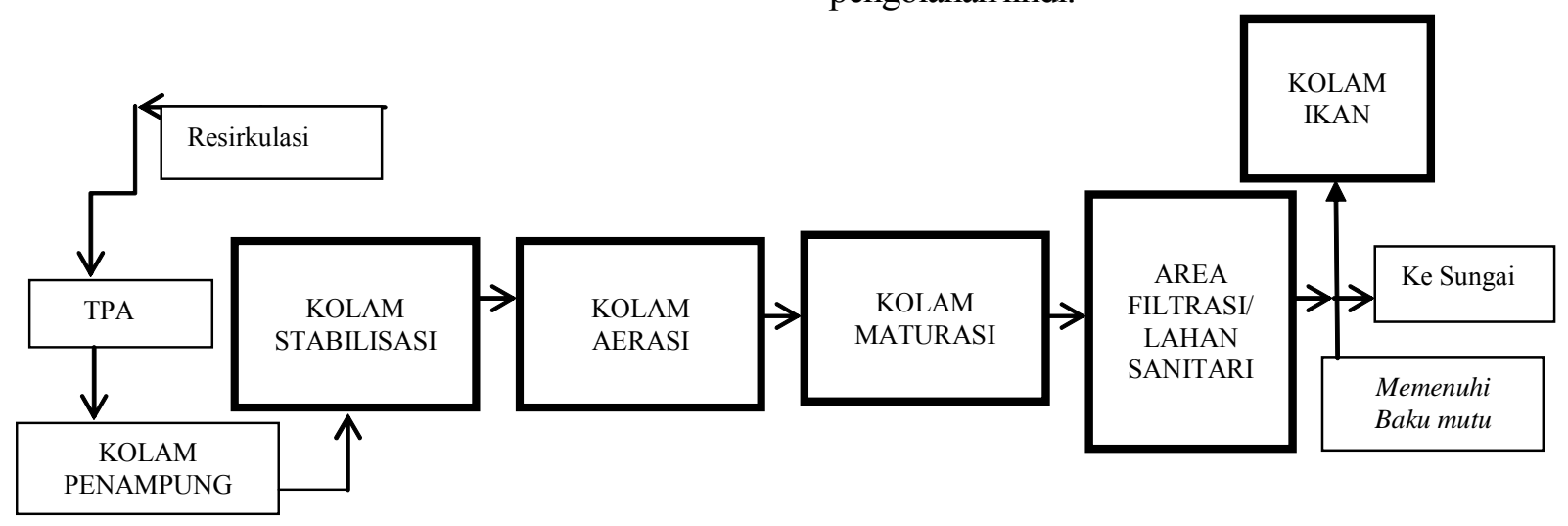

Gambar 4. Skema Instalasi Pengolah Lindi

Ambang batas kualitas olahan yang diperkenankan dibuang ke badan air penerima diatur oleh masing-masing daerah.Semakin ketat nilai ambang batasnya, maka dituntut efisiensi pengolahan air

leachate yang semakin tinggi. Beberapa kualitas hasil olahan yang diharapkan menurut peraturan yang berlaku di Indonesia adalah sebagai berikut :

Tabel 5. Beberapa Baku Mutu yang berlaku di Indonesia

\begin{tabular}{|c|c|c|c|c|c|}
\hline \multirow[b]{2}{*}{ Klasifikasi } & BOD5 & COD & \multirow[b]{2}{*}{$\mathrm{pH}$} & \multirow{2}{*}{$\begin{array}{c}\sum N \\
\text { Anorganik } \\
\mathrm{mg} / \mathrm{L}\end{array}$} & \multirow{2}{*}{$\frac{\mathrm{ss}}{\mathrm{mg} / \mathrm{L}}$} \\
\hline & $\mathrm{mg} / \mathrm{L}$ & $\mathrm{mg} / \mathrm{L}$ & & & \\
\hline Gol 1 & 20 & 40 & 9-Jun & 10,88 & 100 \\
\hline Gol II & 50 & 100 & 9-Jun & 22 & 200 \\
\hline Gol III & 150 & 300 & 9-Jun & 38 & 400 \\
\hline Gol IV & 300 & 600 & 9-Jun & 75 & 500 \\
\hline
\end{tabular}

Sumber: Keputusan Menntri Lingkungan Hidup 03/91

\section{Kolam Stabilisasi}

Kolam stabilisasi ini selain dapat menurunkan kadar BOD dan COD juga dapat menurunkan jumlah fecal coli yang ada dalam leachate. Namun untuk pengolahan lindi sebaiknya menggunakan kolam anaerobik/ fakultatif karena sangat tingginya kadar BOD.
Adapun hasil pengolahan dari kolam stabilisasi ini adalah sebagai berikut :

- Efisiensi pengolahan (60-80\%)

- Dari hasil penelitian kadungan $\mathrm{BOD}_{5}$ pada TPA Supit Urang $=3968,293 \mathrm{mg} /$ liter

- Dari hasil penelitian kadungan COD pada TPASupit Urang $=8960 \mathrm{mg} /$ liter. 
Setelah melalui tahap penyisihan di kolam stabilisasi maka di ketahui kadar $\mathrm{BOD}_{5}=1.322,76 \mathrm{mg} /$ liter, dan kadar COD $=2986,67 \mathrm{mg} /$ liter Atau biasanya mempunyai efisiensi antara $50-85 \%$.

\section{Kolam Aerasi}

Untuk memenuhi kebutuhan oksigen, kolam aerasi dilengkapi dengan aerator yang mempunyai fungsi mensuplai oksigen yang diperlukan untuk menurunkan kadar BOD/COD. Adapun pengolahan limbah lindi pada kolam aerasi secara mekanis adalah sebagai berikut :

- Efisiensi konversi $\mathrm{BOD}_{5}$ : 75 - 90\%.

- Efisiensi konversi COD : 65 - 90\%.

Setelah melalui tahap penyisihan di kolam aerasi maka di ketahui kadar $\mathrm{BOD}_{5}=264,55 \mathrm{mg} / \mathrm{liter}$, dan kadar $\mathrm{COD}=746,67 \mathrm{mg} /$ liter.

\section{Kolam Maturasi}

Dengan demikian sinar matahari sangat berperan di kolam maturasi ini dikarnakan sinar matahari dapat membasmi bakteri yang terdapat pada kolam maturasi. Di kolam ini pun terjadi simbiosis antara bakteri dan algae. Hanya saja, diharapkan bakterinya dapat dibasmi sebelum dibuang ke sungai. Algaenya juga jangan sampai banyak yang masuk ke sungai agar tidak menurunkan kulaitas air sungai. Efisiensi konversi $\mathrm{BOD}_{5}$ dan COD : 50\%.

\section{Land Treatment (Rapid-Infiltrated Plant)}

Matoda Rapid Infiltrated Plant adalah metoda pengolahan lindi dengan cara meresapkan cairan lindi pada suatu lahan yang ditanami tumbuhan tertentu. Tumbuhan yang dipilih adalah tumbuhan yang memiliki kriteria sebagai berikut :

Tumbuhan berbuluh, tumbuhan ini lebih efektif meresap air dan kemudian mengevapotranspirasikannya lebih besar.

Memiliki nilai ekonomis atau murah dalam pengadaannya karena tumbuhan tersebut akan menjadi media yang "dikorbankan".

\section{KESIMPILAN DAN SARAN}

\section{Kesimpulan}

Prediksi Produksi air lindi maksimal yang dihasilkan tahun 2011, adalah $\mathrm{Lo}=0,8 \mathrm{~m}^{3} /$ hari. Dan debit air lindi yang dihasilkan untuk rencana kolam penampung $\mathrm{Q}=9,43 \mathrm{~m}^{3} /$ hari

Untuk menampung air lindi tersebut diperlukan dua kolam penampung dan empat kolam pengolahan air lindi, dimensi kolam penampung pertama dan kedua adalah panjang $8 \mathrm{~m}$, lebar $8 \mathrm{~m}$ dan dalam 2,5 $\mathrm{m}$. Kolam stabilisasi dan maturasi dengan berdimensi panjang 4 $\mathrm{m}$, lebar $2 \mathrm{~m}$, dalam $2 \mathrm{~m}$. Dimensi kolam aerasi adalah panjang $2 \mathrm{~m}$, lebar $2 \mathrm{~m}$, dalam $2 \mathrm{~m}$. dimensi kolam filtrasi-sorpsi adalah panjang $3 \mathrm{~m}$, lebar $3 \mathrm{~m}$ dan dalam $2 \mathrm{~m}$.

Dari unit pengolahan limbah kadar COD $=8960$ $\mathrm{mg} / \mathrm{l}$ dan $\mathrm{BOD}_{5}=3968,293 \mathrm{mg} / \mathrm{l}$, setelah melalui instalasi pengolahan limbah maka menjadi COD = $298,67 \mathrm{mg} / \mathrm{l}$ dan $\mathrm{BOD}_{5}=88,18 \mathrm{mg} / \mathrm{l}$. Dari hasil pengolahan di kolam ke tiga ini kadar sudah memenuhi baku mutu golongan III Keputusan Menteri 03/91.

\section{Saran}

1. Perlu adanya perhitungan untuk mengetahui kondisi dan kualitas sampah lama yang sudah ditimbun, apabila memungkinkan dapat digunakan sebagai tanah penutup.

2. Perencanaan Sanitary Landfill pada lahan pengembangan TPA Supit urang Malang ini perlu ditindak lanjuti dengan perencanaan detail desain dan rincian biaya yang dibutuhkan.

3. Perlu adanya pengolahan limbah air lindi yang selalu di control agar tidak mencemari lingkungan sekitar TPA Supit Urang Malang.

4. Perlu adanya pemilahan sampah untuk logam berat dan radio aktif. Karena sampah logam berat dan radio aktif sangat berbahaya.

\section{DAFTAR PUSTAKA}

Alfiandy Devri, 2003, Pengelolaan Leachate Di Tempat Pembuangan Akhir (TPA) Tompogunung, Kabupaten Semarang, Universitas Diponegoro Semarang. 
Damanhuri, 2008, Landfilling limbah, Fakultas Teknik Sipil danLingkungan-Institut Teknologi Bandung.

Direktorat PLP, Ditjen Cipta Karya, Departemen PU, 1992 Persampahan, Petunjuk Perencanaan Taknis Dan Managemen, Jakarta.

Keputusan Menteri negara Lingkungan Hidup, nomor 03 tahun 1991 tantang Baku Mutu air yang berlaku di Indonesia.

Klosterman, Richard E. 1990. Community Analysis and Planning Techniques. Savage.Rowman \& Littlefield, 1990.

Martono Djoko Heru, 1996, Pengendalian Air Kotor (Leachate) Dari Tempat Pembuangan Akhir (TPA) Sampah, Analisis Sistem Badan Pengkajian Penerapan Teknologi, Jakarta.

Pichtel, J. 2005, Waste, Its Origin, Its Destination . CRC Press, Amerika Serikat.

Smith, Stanley, Jeff, Tayman, and David, Swanson. 2001. State and Local Population Projections: Methodology and Analysis. New York. Kluwer Academic/ Plenum Publishers.

Tchobanoglous, G., Theisen, H., dan Vigil, S. 1993. Integrated Solid Waste Management : Engineering Principles And Management Issues. New York: Mc Graw-Hill International Editions 